\title{
Low Impact Development Intensive Rural Construction Planning in Xu Fu Village Ningbo, China: Perspective Review through Rural Resilience Perspective
}

\author{
Roosmayri Lovina Hermaputi ${ }^{1}$ \\ Department of Urban and Rural Planning, Zhejiang University \\ Hangzhou, People's Republic of China
}

\section{Chen Hua}

Department of Urban and Rural Planning, Zhejiang University

Hangzhou, People's Republic of China

Artikel Masuk : 24 Februari 2017

Artikel Diterima : 5 Mei 2017

Tersedia Online : 29 Agustus 2017

\begin{abstract}
Xu Fu Village Ningbo LID Intensive Rural Construction Planning is a cooperation project between Zhejiang University and Ningbo Institute of Technology which named "12th Five-Year National Science and Technology support program-the comprehensive demonstration of the key technology of the beautiful rural construction in the rapid urbanization area of the Yangtze River Delta". This plan focuses on intensive rural construction as part of rural development and construction project that applies the principles of low impact development. Xu Fu Village located in the Yangtze River Delta Region. Currently, the rural growth brings the high impact of development, as a result of rapid urbanization growth arising several issues, such as low land use efficiency, dispersed rural residence, homestead occupies more, rural roads covering over, etc. Meanwhile, $\mathrm{Xu}$ Fu village wishes to develop its tourism potential. Thus, the intensive rural construction should be done to avoid the severe effect. The project result hopefully can improve the quality and level of rural residential planning, design, and construction; improve their living environment; save construction land and water use; and improve energy efficiency. The aim of this study is to review the Low Impact Development (LID) Intensive Rural Construction in Xu Fu Village, Ningbo City through the rural resilience perspective. This paper will describe the project plan first, then review it through rural resilience perspective. This paper will elaborate the rural resilience theory and then review the rural resiliency through two parts; the first part is identifying rural resilience in rural infrastructure development based on the criteria created by Ayyob S. and Yoshiki Y. (2014), about urban resiliency criteria, and then the second part is reviewing $\mathrm{Xu} F u$ Village resilience through Arup Resilience Qualities (2012), considering three rural resilience domain (economy, ecology, and cultural).
\end{abstract}

Keywords: low impact development, intensive rural construction, planning, rural resilience

\footnotetext{
${ }^{1}$ Korespondensi Penulis: Department of Urban and Rural Planning, Zhejiang University

Email: roselocious@gmail.com
} 


\section{Introduction}

\section{Background Study}

Rural development should adopt the principles of sustainability. Sustainable rural development includes integrated status and the coordination between agricultural resources, environment, and rural socio-economic development. In 2014, China's urbanization level reached $54.77 \%$ from total China's population. What significant progress with more than half of the Chinese now live in cities is an accumulative outcome of rapid urban growth in the past 40 years (Zhang \& Han, 2009). Recently, the gap between rural and urban China keeps expanding. For instance, the income ratio of urban residents to rural residents was 2.79 in 2000 and 3.331 in 2007. This revenue gap becomes a severe problem since it associated with the different living standards, life quality, and public services. The difference along with the uncoordinated development of urban and rural areas usually happened at a various stage of country development. It is the consequence of the rapid economic growth of China. The worst case is "empty villages" since rural population starts to move into urban areas seeking better living standards (Liu, Zhang, \& Zhang, 2009). The primary solution to this problem lies in a reconstruction and revitalizing rural areas along with the establishment of better rural regional policies. All these steps should apply the principles of sustainability.

Recently the Chinese Central Government execute the "three 100 million people", means that it will be 100 million rural population to settle in cities and town, 100 million urban residents to settle in shantytowns or developed urban villages, and 100 million new urban dwellers to settle in the central and western regions. Chinese Premier "Li Keqiang" set this strategy as a fundamental way to reduce the disparity between China's urban and rural areas $(\mathrm{Gu}, \mathrm{Li}, \&$ Han, 2015). However retrace the slow development of small towns has become an obstacle in Chinese urbanization (Ma, 2005). There are several issues stand behind it which connected with its large quantity but small size population, single economic activity domination, a weak economy and poor financial situation, and lack of governance system (Gu et al., 2015). Appropriate steps needed to resolve the issues so as to promote better rural regional development.

The aim of this study is to review the Low Impact Development (LID) Intensive Rural Construction in $\mathrm{Xu} F u$ Village, Ningbo City through the rural resilience perspective. Xu Fu Village located in the Yangtze River Delta Region. The village has a total population of 1633 people, 667 households, and 1,240 acres of arable land in 2014 and agricultural output value 1.91 billion yuan with 29,800 yuan per capita income of the villagers. The villagers mainly workers and supplemented by farming, the local industry including rubber products production and processing of secondary industry. Xu Fu Village relies on tourist attractions advantages, and scenic supporting the development of rural tourism. Over the years, the village collective has been named the honorary title of civilized national village, the national respect for the model village, Zhejiang province level civilized village, party-building model villages and the most beautiful villages in Zhejiang Province and so on. Before the year 2009, the development focuses on the completion of the construction of the $\mathrm{Xu} F \mathrm{Fu}$ Village New District including the villas, row houses and apartments for the elderly in the form of resettlement of 276 households. Until now there are about 440 of the remaining households living in the old village area. However, the old village has no space in front of the house is relatively narrow, traffic and parking are difficult, infrastructure was difficult to place, and village environment is difficult to control. Moreover, the villagers desire for more housing as well as develop their local tourism potential. Along with $\mathrm{Xu} F \mathrm{Fu}$ Village of the rapid development process, the high impact development emerged as a result of rapid urbanization. It raised several matters such as low land use efficiency, dispersed rural residence, homestead over occupies, insufficient infrastructures (road, water resource, and sewage infrastructure). Moreover, Xu Fu Village located in Yangtze River Delta region which 
hot in summer and cold in winter has large energy consumption. The full use of solar energy conservation and widespread utilization of technology for building rural construction is an important issue for local rural development. To address the local issues, the Low Impact Development Intensive Rural Construction Project was taken place in Xu Fu Village. This rural development and construction project goals are to improve the quality and level of rural residential planning, design, and construction; improve their living environment; save construction land and water use; and improve energy efficiency. New intensive rural construction concept will not only environmentally friendly, energy-efficient and integrated with important guiding significance but also will promote old village transformation and new rural construction in Ningbo City area that offers comprehensive technical support and demonstration. Xu Fu Village's low impact development intensive rural reconstruction project does not only promote environmental management through constructing the environmentally friendly architecture rural housing but also the application of Low Impact Development (LID) Storm water Management System and the construction of green energy.

Rural is the forms of a group of people who lived in traditional forms, have a very close kinship each other. It is also a place where nature still pure and well conserved. The people live in rural mostly live for agricultural, fisheries, and other primary home industry. Meanwhile, The Low Impact Development (referred as LID) is a green storm water management approach to handling surface water flow and management through green infrastructure and vegetation. Low Impact development contains three steps "to avoid the impact, minimizing the impact, and managing the impact" to maximize the retention structure and function of the existing site and hydrology ecosystem. LID facilities mainly have structure and function. The entire structure of water ecology system services has the role to improve the unexpected contaminants and to integrate environmental pollutants. Each facility has the function from the "control - retention - holding" to "slow down penetration - handling," the pollution treatment facilities from mechanical into biological type (Feng, Dong, \& Zhang, 2006). The term LID distinguishes the site-design and catchmentwide approach from the typical storm water management approach and typically involved transport to large end-of-pipe detention systems. LID is smaller scale storm water treatment devices located near the runoff area; these devices can be in the form of the bio-retention systems, green roofs, and swales, located at or near the source of runoff. LID may reduce the utilization of hard infrastructures such as paving, curb, gutter, pipe systems, and inlet structure by using the water features to reduce the extent water quality effects of impervious surfaces with reduced infrastructure construction and maintenance costs.

In this study, the "intensive rural construction" contains land, also includes land and improve overall performance. Specifically under the premise of protecting the ecological function of the countryside. While rural culture well preserved. The unchanged farmland, the built-up area per capita constant, intensive measures taken science-intensive traditional village renovation to respond to demographic changes, changes in the industry and enhance the quality of living, the formation of "intensive, saving, integrated, environmentally friendly," of the modern village. The Soviet Economist interpret "Intensive" as relatively extensive, based on benefits (social and economic) as a fundamental restructuring of the business of various elements to achieve the minimum cost for maximum investment (Alexandre, 1967). The intensive construction refers to an urban architecture in possession of limited land resources under the premise of a compact, efficient and orderly functional organization model (Urban Design \& Architecture Integration). Thus, intensive rural construction refers to the action of creating a high-density development and has a particular economic, social, and ecological benefit of building groups to create sustainable rural development. Also, construction of a modern country describes "intensive" as benefits (social and economic) as a primary production, elements of life in rural areas to restructure to minimize costs and 
improve the efficiency of land use per unit area in village development and village construction.

This paper reviews the rural construction project based on rural resilience perspective. Rural resilience related to the terms of adaptation, rapid recovery, and flexibility. It is the rural capacity to handle and adapt to ecological, cultural, and economic changing so as to retain its normal condition. It is including flexibility to face the change of rural management and governance failure. United nation defined rural resilience as the action to reduce the shocks risk, transfer, reserves, and prevent it (Winderl, 2014). The ecological, social, and economic stand as the rural resilience's domain, each domain influencing each other. A rural area may be defined as a social system that interacting and relies on an ecological system (natural resources) while the natural resources and environment are conditioned by the action of society. Rescia, Pons, Lomba, Esteban, \& Dover (2008) explained that the socioecological system or rural including several subsystems that interact each other. The highlight of the scheme is the role of government to make sure the system works well, and the resilient socio-ecological system can achieve if the region is ecological, economically, and socially sustainable. Each of subsystems and its components together creates a holistic complex adaptive system. The adaptive capacity of the rural system is one of the features of resilience. The unbalance adaptive capacity of each system will lead the loss of resilient (Walker \& Salt, 2006). Therefore the balance interaction within and between system is the primary key to achieving rural resilient. Rural systems also associated with diversity, interdependence, and interconnection. Multiple components of the system together protect the system cope the disturbances, diverse function of elements of the rural system make the rural less vulnerable (Folke, Carpenter, Elmqvist, Gunderson, \& Walker, 2002). Furthermore, the interconnection related to how each component of the system connect each other involving the exchange of knowledge, financial capital, services, and goods to support between the parts and together strengthening the system. Meanwhile, the interdependencerelated to collaboration between each component to enhance the system that makes the system is able to handle the unforeseen disturbances and adapt with rural development forces.

\section{Methods}

Recently, the rural construction and development have become the main agenda of China Government. China's rural areas have lagged behind severely compare to their urban areas; there is such a gap of the economic base, services, and infrastructures among urban and rural areas. Several problems in rural construction and development project still existed such scattered population distribution; natural villages; the small village-scale pattern has not been fundamentally changed' and the residential wasteland phenomenon is still evident. Thus, the need for transformation of the eastern coastal village of new rural construction and new technology integration and optimization. Xu Fu Village's low impact development intensive rural construction project does not only promote environmental management through constructing the environmentally friendly architecture rural housing but also the application of Low Impact Development (LID) Storm water Management System and The construction of green energy. The project aims to build Ningbo region to promote "intensive" renovation of old villages in the scientific planning, to protect the village ecological functions, cultural functions, saving land, and to achieve sustainable development and the environment, intensive functional effect, building a better living environment of a modern country. This project plan itself is a corporation of Zhejiang University and Ningbo Institute of Technology under "Villages of Ningbo city reconstruction and new rural construction technology integration and demonstration" project. 
This paper aims to review the programs in Xu Fu Village's low impact development intensive rural construction project through rural resilience perspective. The reason why this article tries to review in rural resilience perspective is that rural resilience opens up the idea that there are different balances possible within a rural area and address the gap between rural-urban. Along with modernization, the increasing of rural demand, and the future disturbances, and insufficient rural human resources capability to filter, absorb, and adapt rapidly, emphasize the need of rural for being resilience. Resilience is the answer to address the vulnerabilities issue. Thus, the rural resilience needs to be considered in rural development practice.

This paper will describe the project plan at first, and then review it through rural resilience perspective. This paper will conduct qualitative analysis to elaborate the rural resilience theory and then review the rural resiliency through two parts; the first part is identifying rural resilience in rural infrastructure development based on the criteria created by Sharifi \& Yamagata (2014) about urban resilience criteria, and then the second part is reviewing Xu Fu Village resilience through Arup (2012) considering three rural resilience domain (economy, ecology, and cultural). The reason behind using city resilience qualities to assess rural resilience is because both urban and rural development is involving local government and local society in practice and the urban and rural system also embody the same dimension such as social, ecology, economy, politic, and infrastructure. Moreover, good rural development should meet the needs and balance on its ecosystem, economic, and cultural functions. These three domains connect and influence each other which can create rural intensity or vulnerability. Realizing the difference between urban and rural terms thus the review will only be done based on rural term.

\section{Xu Fu Village Intensive Construction Planning Review}

\section{Planning Background, Objectives, and Principal}

The impact of development as a result of rapid urbanization raised several matters in $\mathrm{Xu} F u$ Village such as low land use efficiency, dispersed rural residence, homestead occupies more, rural roads covering over, etc. The Low Impact Development Intensive Rural Construction Project was carried out to address the local issues. The planning objectives are the transformation of old villages; the land conservation; create environment-friendly village; healthy development of the industry, and cultural harmony "intensive" Modern Xu Fu village. The primary orientation of the plan is a village located in a suburban area that promotes tourism, modern agriculture and green industry based on "intensive" modern village. The Xu Fu Village Low Impact Development Intensive Rural Construction Plan has several planning principles, such as:

a) Conservation principles: resource conservation planning key village lies in land conservation, land conservation, production capacity, construction land does not increase, the basic farmland does not reduce;

b) Intensive principles: pluralism industry, health, sustainable development, mixed land use, energy efficiency per unit area of land;

c) Environmental principles: ecological health, to respect the history, culture and landscape style village.

d) Integrated principles: balance the needs of various production and living, transportation and entertainment villagers, using integrated way to improve the quality of life of the villagers. 


\section{Planning Program of Xu Fu Village LID Intensive Rural Construction}

$\mathrm{Xu} \mathrm{Fu}$ Village Ningbo rural construction and development project is a cooperation project between Zhejiang University and Ningbo Institute of Technology which named "12th Five-Year National Science and Technology support program-The comprehensive demonstration of the key technology of the beautiful rural construction in the rapid urbanization area of the Yangtze River Delta". This plan focuses on intensive rural construction as part of rural development and construction project that applies the principles of low impact development. There are three innovations of this plan are:

a) Construction focuses on the rural character of the Yangtze River Delta region, construction design, construction models, the formation of low impact development and integration of solar energy construction and demonstration. The main focus of the construction is green building technology and integration and demonstration in rural areas.

b) Implementation of energy independent village with efficient use of solar energy and biomass energy include control systems are reliable and comprehensive.

c) Infrastructure construction using low impact development for rainwater sewage and organic waste in rural residential areas.

This project was set up on the outskirts of Xu Fu Village to achieve the integration of urban and rural development. The villagers will gradually accept the modern country (under urban and rural) lifestyle. The intensification of the village is a useful way to village modernization process. It is a long process for the village to transform the social and economic structure. Thus, during the process, it is necessary to respect the villagers living habits and rural and cultural traditions to achieve healthy and sustainable development. The difference of $\mathrm{Xu} \mathrm{Fu}$ Village appearance pre and post development can be seen in Figure 1 and Figure 2. Meanwhile, the programs included in this plan can be seen in Table 1.

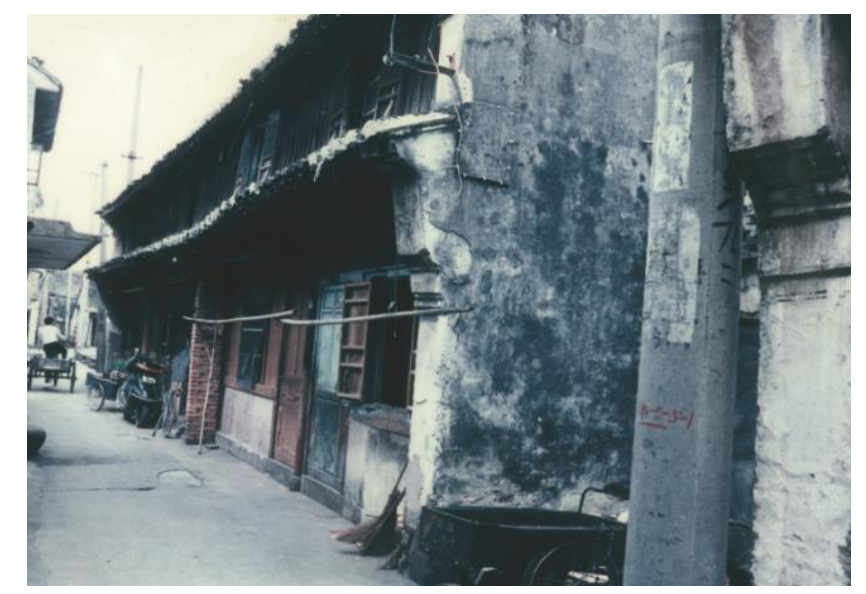

Source: Zhejiang University and Ningbo Institute of Technology, 2016

Figure 1. Xu Fu Village Before 2009 


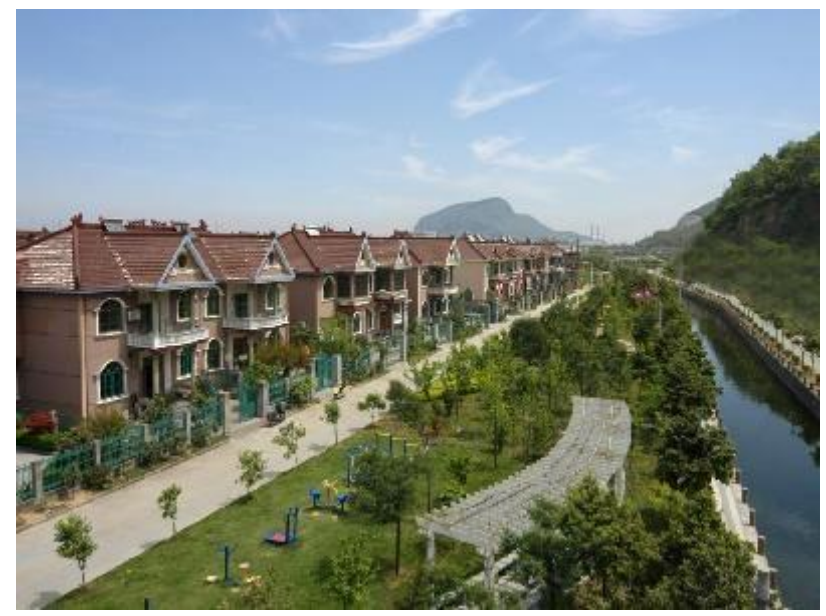

Source: Zhejiang University and Ningbo Institute of Technology, 2016

Figure 2. Xu Fu New Village

Table 1. Programs of Xu Fu Village LID Intensive Rural Construction Plan

\begin{tabular}{lr}
\hline \multicolumn{2}{c}{ Program } \\
\hline $\mathrm{Xu} \quad \mathrm{Fu}$ & Village \\
Farmer's & Residential \\
Apartment & Layout \\
Optimization Design
\end{tabular}

Optimization Rural Building Design:

a) South Residential Unit will use two sets of apartment layout design optimization, has four layers of semi-basement and attic in total. Including the semi-basement garage, bicycle garage, and storage room, one unit will occupy four households. Each household has a separate upstairs downstairs living space, ground and roof garden, independent car garage and storage room.

b) North Residential Unit will use one unit layout, each unit will have four level, the first level use for garage and storage space, meanwhile, second till the fourth level use for housing, and upstairs have private and public roof garden.

Residential apartment layout most north of a unit as a unit. The remaining four is a two story, with a living room, dining room, kitchen, bathroom, bedroom, each one, by indoor stairs to the three floor, three floor has four bedrooms, private roof garden, and there is also a public roof garden. (Residential unit design can be seen in fig.3)

Applying Integrated To optimize energy efficiency, wall insulation system construction technique Technology To is used to strengthen the thermal insulation of the building envelope. Thermal Optimize The Energy insulation and energy saving technology through building doors and windows Efficiency Of New that affect the indoor thermal environment quality and energy efficiency. Buildings And Control of wall and window ratio through the choice of door and window Existing Buildings materials to enhance energy efficiency. Also, roof insulation construction technology Thermal insulation design will also be applied to building the general thermal insulation roof, upside down type roof, planting roof and water storage roof.

\begin{tabular}{ll}
\hline $\begin{array}{l}\text { Optimization And } \\
\text { Integration of New }\end{array}$ & $\begin{array}{l}\text { Using the new non-renewable clinker slag powder composite cementitious } \\
\text { material, apply phase transition of wall insulation putty, using R \& D building } \\
\text { silt soils unburned ceramic preparation technology, and also utilization of new } \\
\text { Energy-Saving } \\
\text { Materials }\end{array}$ \\
$\begin{array}{ll}\text { Green Energy-Saving straw waste material. } \\
\text { Technology }\end{array}$ & $\begin{array}{l}\text { Using thermal insulation wall technology. Block wall insulation form and } \\
\text { system in hot summer and cold winter area. The thermal insulation is optimal } \\
\text { Integration Of Rural } \\
\text { in hot summer and cold winter area insulation form. Energy saving wall } \\
\text { investment can be quickly recovered; external insulation will save both energy }\end{array}$ \\
\hline
\end{tabular}




\begin{tabular}{|c|c|}
\hline Program & Program Description \\
\hline $\begin{array}{l}\text { Housing Construction } \\
\text { Safety }\end{array}$ & $\begin{array}{l}\text { and money; and energy saving wall can improve the living comfort, reduce } \\
\text { the energy saving of air pollution and greenhouse effect cannot use the money } \\
\text { to measure benefit. If we look from the various angle, building energy saving } \\
\text { is not only cost-effective but also is the shadow and posterity, high efficiency. }\end{array}$ \\
\hline $\begin{array}{l}\text { Energy-Saving } \\
\text { Environmental } \\
\text { Protection Of Rural } \\
\text { Housing Construction } \\
\text { Whole Process } \\
\text { Management }\end{array}$ & $\begin{array}{l}\text { The whole management process of the project will consider the PPP, using } \\
\text { operation period compensation mode where the government only plays a role } \\
\text { in the process of project construction during the construction period of the } \\
\text { project. During the operating period of the project, the government to invest } \\
\text { in infrastructure projects, such as compensation or profit distribution, etc. This } \\
\text { model has the advantages that the government can reduce the amount of } \\
\text { investment in the earlier stage of project construction, is conducive to ease the } \\
\text { financial pressure of the government; forecast profit through redistribution } \\
\text { beyond, effectively generate incentive and constraint on company item and } \\
\text { fully mobilize the enthusiasm of the company item. }\end{array}$ \\
\hline $\begin{array}{l}\text { Drainage And Rural } \\
\text { Sub-Quality } \\
\text { Ecological Treatment } \\
\text { Technology To } \\
\text { Optimize Integration }\end{array}$ & $\begin{array}{l}\text { Using the rainwater and sewage recycling model of "rainwater collection } \\
\text { system, ecological purification system, and rainwater quality promotion } \\
\text { system." The project aimed at low processing cost, high nitrogen and } \\
\text { phosphorus removal, the rain and sewage treatment and rural village water } \\
\text { environmental ecological restoration, ecological embankment, and landscape } \\
\text { water permeable pavement purification and reuse irrigation demand for the } \\
\text { organic combination. Several technologies that will be applied such as } \\
\text { stabilization pond reinforcement system, artificial rapid infiltration system } \\
\text { (CRI), combined constructed wetland system }\end{array}$ \\
\hline
\end{tabular}

Rural Water Saving Xu Fu Village implements the surface water's sewage diversion project, 90\% And Rain Sewage sewage into the sewage pipe network, the sewer management, reduce runoff Recycling Technology pollution. There also applied a set of comprehensive river bypass purification To Optimize equipment and systems below:

Integration $\quad$ a) The rainwater flocculation and purification system: the purification of rainwater, to achieve the mixed water reuse standards, equipment design, and purification capacity;

b) The water bypass and ecological dialysis system, In the algae season, adding auxiliary head environmental preparation, control algae generation, automatic control; maintaining the water power cycle, and extra drop aeration during the rainy season.

c) The installation of ecological floating island main overwintering aquatic plant of Siberia iris, with few floating plants, the formation of good landscape effect;

d) Biological contact oxidation method and activated sludge process were combined to control the pollution sources. A filler in the sources of pollution emissions, on indigenous microbial compounds by microbial screening, part fixing, suspension, combined aeration can efficiently handle wastewater discharged into the river.

Village Road Using recycled concrete aggregate water permeable concrete pavement Reconstruction New typical structure. The permeable cement concrete pavement paved with high Technology strength and stiffness and had the performance of plate. So the recycled Integration concrete aggregate theory of porous cement concrete pavement stress analysis can refer to "rigid pavement design."

Source: Zhejiang University and Ningbo Institute of Technology, 2016: 11-81 


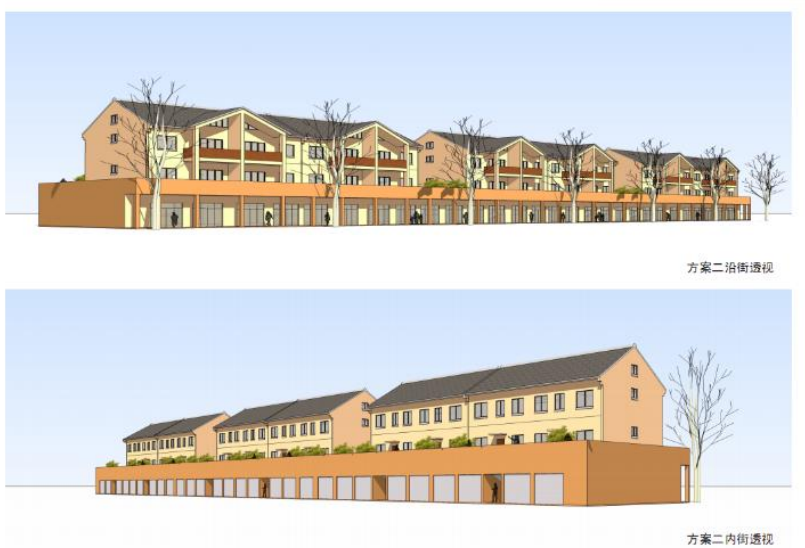

Source: Zhejiang University and Ningbo Institute of Technology, 2016

Figure 3. Residential Unit Design of Xu Fu Village Intensive Construction Plan

\section{Review from the Rural Resilience Perspective}

\section{Rural Resilience Theory}

Rapid urbanization has been the remarkable phenomenon lead the massive change in environment, social life, and culture in the urban areas and its countryside. This fast growth and change are not followed by the readiness of impact recipient, especially in rural area. Rural characterized by traditional life, agricultural-based economy, dispersed settlement, and stable social relationship. However along with rapid changes, the influence of urban culture and advances in science and technology make rustic character changed, lifestyles, and development of infrastructure, facilities, and housing designs are not correspond to the original character of the countryside. The fast growth of urbanization produced high impact development where the massive land conversion and urban-rural constructions affected the balance of ecosystems. High impact development evoked the urban-rural economic gap, disaster-prone rural area, low land use efficiency, loss of rural identity, and lack of energy resource. Therefore sustainable rural development is needed to address the high impact development issues. Ploeg, Jingzhong, Schneider, \& Douwe (2010) describe the rural development objectives in a coordinated set of reduction of poverty, securing positive externalities, and safeguarding family farming. Meanwhile, sustainable rural development goal is to improve the quality of life for the rural people by developing capacities that promote community participation, health and education, food security, environmental protection and sustainable economic growth. The development also should meet the needs of present and future generation.

Recently the "resilience" concept arise and become a comprehensive way to promoting sustainable urban and rural. At the earlier study of resilience, Holling (1973) described resilience as the ability of the socio-ecological system to accommodate sudden shocks and disturbances without experiencing changes to the system. The resilience of places refers to the ability to survive (Barata-Salgueiro \& Erkip, 2014), adapt, and resistance from economic, environment, and social shocks and disasters and fast recovery to its original position after receiving a disruption (Ding \& Hu, 2016; Scott, 2013; Skerratt, 2013; Wilson, 2012). Rural resilience itself is the resistance of rural to withstand of changes on its economic, environment and social condition. Resilience connects to the sustainability, the place which resilience it does sustainable, however, the place which sustainable can be not resilience, so 
far resilience term can be used as the indicator to assess sustainability. Many researchers have analyzed the concept and connotation of resilience in different contexts, including engineering resilience, economic resilience, ecological resilience, community resilience, governance resilience, and so on (Hosseini, Barker, \& Ramirez-Marquez, 2016). Likewise sustainability, resilience majorly presented in qualitative terms.

A resilient system, according to Hudson (2010) and Wardekker, de Jong, Knoop, \& van der Sluijs (2010) is an adaptive system that can tolerate disturbances (events and trends) by respond, recover, adapt, and adjust quickly in ways that do not damage efficient operation, remain to the existing developmental path or transform into a new one. The system can reorganize further disturbance-driven change. In the context of rural studies, Schouten (2009) describe the resilient system as the rural system itself. Rural system's subsystems including society, environment, government, and economic. A rural area may be defined as a social system that interacting and relies on an ecological system (natural resources) while the natural resources and environment are conditioned by the action of society. (Rescia et al., 2008) explained that the socioecological system or rural including several subsystems that interact each other. The ecological, cultural, and economic stands as the rural resilience domain, each domain influencing each other. If a rural would not be resilient economically means that region is more vulnerable to get economic shocks. The shocks will bring out the ecological problems, such as abandoned agricultural land, food and fresh water scarcity, and significant damage to green infrastructure that reduces ecological resilience. Moreover, the presence of sufficient human capital in the region will decrease and worsen the overall rural capacity to be resilient. Therefore, a declining cultural resilience contributes to the vulnerability of the rural system. Resilience study regarding development mostly did in urban or city scopes. It rarely in rural scopes. I argue that the major concept of urban resilience also can be implemented in rural also; however, some measuring devices will adjust the goals of each development, and specified size will be different. This paper of the major references could be attached to urban resilience concept and apply to identify resiliency of rural.

Rural resilience has measurable characteristics, and it is identified by the capacity of the rural system to confront with future changes or shocks. The characteristics refer to the "qualities." The rural system should perform the qualities of rural resilience to evince its resiliency (Godschalk, 2003). There are several studies indicating the resilience qualities. The most resilience qualities mentioned below are found in the context of identifying urban resilience. However, those qualities simultaneously valuable to determine the rural resilience since it involved social and ecological systems which also exist in the rural area. Rural resilience qualities encompass reflectiveness, resourcefulness, robustness, redundancy, flexibility, inclusiveness, and integration (Arup, 2012). However each qualities assessment has own variable and indicator for each theme, so to review resilience comprehensively, the qualitative explanation is the best way to proving the resilience existence. Rural that resilience should demonstrate seven qualities of resilience above. Resilience itself can be the tool for rural development assessment. As urbanization and climate change drives the intensity of disruption on rural economic, social, and environment; the challenges to providing the development to improve rural lives and livelihood also increasing. Therefore the rural development that promoting resilience qualities is urgently needed for addressing rural issues (see Table 2).

Table 2. Arup Resilience Qualities List

\begin{tabular}{ll}
\hline \multicolumn{1}{c}{ Resilience Qualities } & \multicolumn{1}{c}{ Explanation } \\
\hline Reflectiveness & The ability to learn from the past and act in times of crisis \\
\hline Resourcefulness & $\begin{array}{l}\text { Readiness to provide alternative ways to use resources at times of crisis and } \\
\text { facilitate the needs to achieve the goals. }\end{array}$ \\
\hline
\end{tabular}




\begin{tabular}{ll}
\hline \multicolumn{1}{c}{ Resilience Qualities } & \multicolumn{1}{c}{ Explanation } \\
\hline Robustness & $\begin{array}{l}\text { well understood, constructed, and managed to make sure safety and ability } \\
\text { to predict the future failure }\end{array}$ \\
\hline Redundancy & $\begin{array}{l}\text { having spare capacity to accommodate unpredictable pressures and surges } \\
\text { in demand }\end{array}$ \\
\hline Flexibility & The ability to adopt alternative strategies in response to sudden crises \\
\hline Inclusive & $\begin{array}{l}\text { The ability to covering all the services, facilities, or items normally expected } \\
\text { or required. }\end{array}$ \\
\hline Integration & $\begin{array}{l}\text { Capacity to bring together systems and institutions and can also catalyze } \\
\text { additional benefits as resources }\end{array}$ \\
\hline
\end{tabular}

Source: Arup, 2012

A gap between urban and rural development is a standard issue across the country; rural areas are lagging behind socially, economically, and environmentally. In response, the provision of public facilities and infrastructures are applied to address the urban and rural gap issue (Yuan, Zhao, \& Xia, 2013). Coordinated development between urban and rural area relies mostly on the enhancement of infrastructure conditions (Chen, Guo, \& Wu, 2011). The public facilities and infrastructures construction is related to the public facilities and infrastructure building including the restoration, enhancement, and the establishment. The context is usually physical. Since the rural now is not only as the place for food producing but also the place that has diversified functions including recreation, work and living space, environmental services, and water management and purification. The public facilities and infrastructure construction is a key to ensuring the rural economic and ecological development. It becomes the primary demand that boosts rural productivity and activity. The construction can be in the form of street network construction, energy source generator construction, wastewater and runoff water management, and another kind of infrastructure related. Meanwhile, public facilities can be in the form of hospital, school, fire station, public toilet, etc. In the previous research, infrastructure resilience focuses on infrastructure systems which functioning and provide essential services to support the well-being of rural citizens under disturbance events. The infrastructure system including all rural facilities and utilities such as energy power, water supply, telecommunication, housing, health and security centers and so on. Ouyang \& Wang (2015) defined infrastructure system that resilience as its ability to resist, prevent, withstand with any possible hazards and absorb it, then can recover back to the normal operation. $\mathrm{Li}$ (2014) conducted a flexible study planning of green infrastructures. He emphasized that by building green infrastructure can activate the ecological vitality of a city and it can adapt well to actual climate conditions to ensure the continuity of natural ecosystem. He found that multi-scale and diversity in infrastructure system can potentially build the resilience.

Despite using the qualities to identified resiliency, rural resilience also can be identified using some major resilience related criteria. In this Xu Fu Village Project, the theme of review is the infrastructure, whether the construction and development of infrastructure demonstrate resiliency and fulfill the criteria (Sharifi \& Yamagata, 2014). The identification will be present by each sub-theme such as water, energy, spatial configuration and location, green infrastructure, and building and design (see Table 3).

Table 3. Infrastructure Construction That Reflects Resilience Criteria

\begin{tabular}{ll}
\hline \multicolumn{1}{c}{ Sub-Theme } & \multicolumn{1}{c}{ Criteria } \\
\hline Water & Permeable pavement and bioswales, tree canopy, water demand and \\
& consumption, water efficient landscaping, protection of water-sensitive lands \\
& (wetlands, etc.), water demand and conservation systems, water quantity and \\
& quality monitoring, high-efficiency irrigation
\end{tabular}




\begin{tabular}{ll}
\hline \multicolumn{1}{c}{ Sub-Theme } & \multicolumn{1}{c}{ Criteria } \\
\hline Energy & $\begin{array}{l}\text { Energy demand and consumption, flexibility of grid, energy supply systems } \\
\text { for increasing shares of renewable energy, reduce end-use energy demand, } \\
\text { energy monitoring }\end{array}$ \\
\hline $\begin{array}{l}\text { Spatial Configuration } \\
\text { and Location }\end{array}$ & $\begin{array}{l}\text { Street connectivity, pedestrian route connectivity, walking trails that link with } \\
\text { public transportation routes; accessible connection to evacuation routes; } \\
\text { placing inter-dependent infrastructure close to each other; infrastructure } \\
\text { redundancy; urban form (compact, dispersed, poly-centric); density of } \\
\text { buildings; independent infrastructure; urban size and elevation; mixed-use } \\
\text { development; variability and spatial heterogeneity; and avoiding flood plains. }\end{array}$ \\
\hline Green Infrastructure & Parks, forest conservation, waste management \\
\hline Building and Design & $\begin{array}{l}\text { Building insulation, building layout, and orientation, reducing air infiltration } \\
\text { and thermal bridging, natural ventilation, preservation of housing, building } \\
\text { codes, housing age }\end{array}$ \\
\hline
\end{tabular}

Source: Sharifi \& Yamagata, 2014

\section{Rural Resilience Review of Xu Fu Village Low Impact Development Intensive Rural Construction Plan}

\section{Identification of the Resiliency through Infrastructures Construction Plan}

This part will identify the rural resilience from the construction and development of infrastructure plan whether it fulfills the infrastructure resiliency criteria that have been justified by Sharifi \& Yamagata, (2014) or not. The reason behind this identification regards the importance of infrastructure construction to enhance the environmental resilience of the rural. Each sub-theme of infrastructure will be explained by presenting the existence of each criterion from the project plan and then present the importance of the existence and its contribution to realizing rural resilience.

a) Water: $\mathrm{Xu} F u$ village will apply a set of comprehensive river bypass purification equipment and systems to make sure rural water conservation, quantity, and quality monitoring. Village road also will use permeable pavement to accelerate the surface water absorption which will channel to the river. The plan also using the comprehensive river bypass purification equipment and system. The river is the main water resource for villagers; it is used not only for drinking water but also agricultural irrigation. The technology of water purification use the modern equipment to achieve water reuse standard but also using the ecological plant to create beautiful landscape effect. Artificial wetlands also ready to build for water resource bank and efficient landscaping. Technology Monitoring also will take place. Therefore the water quantity and quality of $\mathrm{Xu} \mathrm{Fu}$ Village will be safe and meets the future demand by providing water saving appliances and facilities. Since the planning programs above meets some of the water resilience criteria, then I conclude that the planning of infrastructure construction and development in Xu Fu Village classified as resilience.

b) Energy: $\mathrm{Xu} F u$ village construction will use environmentally friendly architecture and integrated technology of rural housing construction. The project will apply architectural design which optimizes the energy efficiency of new and existing buildings for $\mathrm{Xu} \mathrm{Fu}$ village farmer housing. Energy saving is an important and practical approach to achieving energy resilience. The energy saving building design using the thermal insulation and energy saving technology. Building doors, windows, wall, and roof insulation will affect the indoor thermal environment quality and energy efficiency. In particular, for the roof, thermal insulation of roof is an important part of energy saving building envelope. Despite building design, the selection of building materials also will use the recycled building materials to maximize energy saving such the use of new wall straw waste material, the soils for unburned ceramic, and other energy saving cementitious material. The programs of Xu Fu Village Dwellers Unit Construction Plan 
demonstrate the inclination of energy demand in the housing unit. From this perspective, I argue that the plan promotes energy resilience.

c) Spatial Configuration and Location: $\mathrm{Xu} \mathrm{Fu}$ Village located in suburban areas with specification area development for tourism, modern agriculture and green industry based on "intensive" modern village. The intensive construction of residential land, the plan will do the transformation of old villages remediation and realization of intensive residential (newly built single-family and apartment housing). The principle of spatial configuration in this project is forming a composite unit of land use functions, improve the effectiveness of land use to achieve an intensive effect, also land conservation (per capita construction land does not increase, not reduce the basic farmland). The land use plan will adapt mixed-use land use to promote spatial heterogeneity and try to combined livelihood, industry, agricultural, and tourism in one. The new rural villagers can stay, although the economic and living standards were improved, however, the rural construction and development will not put aside the local culture so that the dwellers can feel more safe, comfortable, healthy, and convenient living environment. Achieving the resilience is the goals of every development, $\mathrm{Xu} F u$ village rural construction plan demonstrate how the spatial configuration and place identity can enhance the rural resilience by providing the more comfortable, productive, and unique place to live.

d) Green Infrastructure: The green infrastructure plays an important role to realize sustainable rural development, promoting the energy saving, and low impact development. Xu Fu Village rural construction planning offer the way of better livelihoods. Building artificial wetland and implement the green roofs become the main focus of the construction. Besides that the plan also considering the waste management by applying garbage collection and treatment management so that the harmless rural domestic waste rate can be reduced. Building the green infrastructure promotes the resilience especially environmental resilience

e) Building and Design: The rural construction project combined the production and life of the peasants. In building and design, the need to fulfill the living habits of farmers and the actual demand in the design of units should also increase the utilization of land. The main focus of the construction is green building technology and integration and demonstration in rural areas. The rural building and design of Xu Fu Village applying the "intensive" principle. It provides living space, production space, storage space, and traffic space at the same time. For the residential unit, the building, and design categorized as an independent house and apartment house. Each house using the thermal insulation technology, the configuration of building layout and orientation, natural ventilation, and also private and public green spaces. Since the plan conforms to the building and design criteria for resilience, so I assume that the planned program promotes the rural resilience.

\section{Review of the Xu Fu Village Construction Plan as Enhancer of Rural Resilience}

In this section, we will discuss in general about the importance of the realization of the implementation of the project to build rural resilience that reflects seven qualities as discussed in Arup resilience frameworks. As it is known that the realization of rural resilience cannot be separated from the three domains of resilience (cultural, economic, and ecology), without the balance and synchronization among that three domain, rural resilience will not be realized. Xu Fu Village is an area that has grown in agriculture and its tourism, but it will be better if it could grow as sustainable and resilience region. Therefore the rural development planning is required. The intensive rural construction planning of Xu Fu Village uses the principles of low impact development and intensive construction. The objective of planning is "to transform the old $\mathrm{Xu} \mathrm{Fu}$ village, the establishment of land conservation, 
beautiful environment, healthy development of the industry, cultural harmony" intensive "Modern Xu Fu Village". It is clearly reflected this plan has the goal to create sustainability and the resilience of the ecological, economic and cultural to build $\mathrm{Xu}$ Fu Village better. Ecological resilience planning can be achieved if well implemented, on the identification of the resilience from infrastructure construction plan, the program of the infrastructures construction promote ecological resilience. Whereas for cultural resilience can be reflected through community involvement in this planning. The plan is obviously considered not only economic benefits but also social benefits. Local culture is still preserved and development matches the needs of local communities in current and future. Society learns and adapts to develop the potential of their village and correspond to problems or shocks that may arise in the future so that cultural resilience can be achieved. Due to achieving rural resilience, economic domain plays an important role also. As the region unable to achieve economic resilience, the region will become vulnerable to any shocks related to wealth and job supply. Thus, the increased vulnerability in economic will influenced the social resilience and ecological resilience. The economic resilience in this plan reflected by the plan principles and objective regarding the acceleration of rural economy through enhance tourism, green infrastructure, and modern agriculture. The existence of tourism, modern agriculture, and green infrastructure will increase the rural revenue, job vacancies, and villager's prosperity. Therefore the rural construction should be implemented well in order to achieve that three domain that creates comprehensive rural resilience.

$\mathrm{Xu} \mathrm{Fu}$ village for years has known as a beautiful village. It's industrial and tourism potential brings the village become more attractive for newcomers to stay and invest in this village. Along with the migration and the increased rural economy, rural development and construction should be a necessity. However, from the year 2009, many constructions took place and currently, old village is running out of space, their livelihood becomes dense; traffic and parking are very difficult; infrastructures are not maintained well, and the village environment becomes more vulnerable. Aware of the rural future needs the rural construction project need to be sustainable and rural can be resilience. The Xu Fu Village LID Intensive Rural Construction plan become the evidence that there is an effort from government to address the rural issues. The construction program selected reflect the ability to cope with the past and current rural crisis. The rural institutions related modify the standards of construction and development. Now they are not only focused on local economic revenue but also ecologically benefits by applying intensive and low impact development principles of rural construction. The plan also occupied many interests by applying PPP mode of rural construction and meet the rural needs to achieve their development goals Thus, the rural construction plan reflects the reflectiveness and resourcefulness qualities.

Robustness, redundancy, and flexibility of this $\mathrm{Xu} F u$ Village construction plan reflect from its ability to utilize their rural assets and potentials to cope the development issues and their willingness to choose several alternative strategies for rapid recovery of their village. Realizing their potential to boost agricultural production, develop tourism, promotes their local culture along with using their asset in the form of lands and wealth capital to build the beautiful Xu Fu Village that comfortable, livable, and sustainable. Xu Fu Village construction plan succeeded in presenting a new concept of rural construction and development that create better livelihood environment, economic benefit, energy-saving, culturally resilience. Since the plan introducing new and applicable technologies of infrastructure construction without leaving behind the traditional practices so the plan reflects the flexibility qualities prominently.

$\mathrm{Xu} \mathrm{Fu}$ village construction project results are expected to improve the quality and level of rural residential planning, design, and construction, to improve their living environment, saving construction land and water use, improve energy efficiency, new rural construction 
intensive, environmentally friendly, energy-efficient and integrated with important guiding significance, and the old village transformation. The inclusive and integrated qualities relate to the performance of good governance, effective leadership, actions to cope multidisciplinary issues to ensure the investment and the development running smoothly. The inclusive quality of each program in $\mathrm{Xu} \mathrm{Fu}$ Village construction plan meets the comprehensive rural needs; the good governance and rural construction management that considered PPP is a great point to achieve resilience. Meanwhile, the integrated quality reflected from synchronization the plan and existing condition that makes the intensive principle itself can be realized. Then the programs selected in the plan enable $\mathrm{Xu} F u$ Village to cope with multidisciplinary issues like climate change, disaster risk reduction, economic crisis, and culture clash in the future. By providing modern agricultural, rural services, infrastructures, and also the cultural and nature preservation, the Xu Fu Village LID Intensive Rural Construction planning successfully demonstrate a good example of rural construction and development.

Rural resilience is needed to fulfill various future demands of rural areas. Basically building rural is not just increase the rural prosperity level but also make sure it resistant with disaster risk. The programs such residential apartment layout optimization design; applying integrated technology to optimize the energy efficiency of new buildings and existing buildings; optimization and integration of new energy-saving materials; green energy-saving technology integration of rural housing construction safety; energy-saving environmental protection of rural housing construction whole process management; drainage and rural subquality ecological treatment technology to optimize integration; rural water saving and rain sewage recycling technology to maximize integration; and village road reconstruction new technology integration are the infrastructure construction and management action. The successful implementation of each program will strengthen the ability to handle and adapt to all existing and future shocks and guarantee the rapid recovery is the essential meaning of rural resilience. All the programs included in the $\mathrm{Xu} \mathrm{Fu}$ Village LID Intensive Rural Construction plan reflect the seven qualities of resilience. Therefore from this perspective, I assume that every rural construction and development should apply various new strategies and technology which can be integrated with the existing rural asset. The good governance, social welfare, cultural preservation, and smart innovation in rural construction development is necessary to achieve rural resilience. However, the main focus to realize rural resilience is how to synchronize each of rural resilience domain (economy, cultural, and ecology). From the identification and review above bring the conclusion that the $\mathrm{Xu} F \mathrm{Fu}$ Village LID Intensive Rural Construction demonstrate the action to build rural resilience. Hopefully, the plan can be implemented well, project objectives can be achieved, and good implementation should go along with monitoring and maintenance for the rural sustainability.

\section{Conclusion}

Rural resilience is the rural capacity to handle and adapt to ecological, cultural, and economic changing so as to retain its normal condition. Rural resilience is needed to fulfill the various future demands of rural areas. Not only the living requirement of villager but also the need to tackle the unpredictable shocks from ecology, economic, and cultural in the future. This paper aims to review the programs in this project through rural resilience perspective. The reason why this paper tries to review the rural resilience perspective is that rural resilience opens up the idea that there are different balances possible within a rural area and address the gap of rural-urban. Xu Fu Village Ningbo LID Intensive Rural Construction Planning is a cooperation project between Zhejiang University and Ningbo Institute of Technology which named "12th Five-Year National Science and Technology support program-The comprehensive demonstration of the key technology of the beautiful rural 
construction in the rapid urbanization area of the Yangtze River Delta". This plan focuses on intensive rural construction as part of rural development and construction project that applies the principles of low impact development. The Xu Fu Village LID Intensive Rural Construction Planning has the objective to transform the old Xu Fu village, the establishment of land conservation, beautiful environment, healthy development of the industry, cultural harmony" intensive "Modern Xu Fu Village." The construction and rural development adapt "three centralized" model, which theoretically can not only save the land, increase the basic farmland, but also conducive to the improvement and protection of the environment. From the planning objectives, the plan compiles many programs. Such as residential apartment layout optimization design; applying integrated technology to optimize the energy efficiency of new buildings and existing buildings; optimization and integration of new energy-saving materials, green energy-saving technology integration of rural housing construction safety; energy-saving environmental protection of rural housing construction whole process management; drainage and rural sub-quality ecological treatment technology to optimize integration; rural water saving and rain sewage recycling technology to optimize integration; and village road reconstruction new technology integration. Those programs reflected the rural resilience from the economy, ecological, and cultural domain. This paper also reviewed the seven qualities of rural resilience, the most prominent point is the flexibility, inclusive and integrated qualities. Flexibility quality reflects from the plan that introducing new and applicable technologies of infrastructure construction without left behind the traditional practices. The inclusive of each plan meets the comprehensive dweller's needs, the good governance, and rural construction management that considered PPP is a great point to achieve resilience. Meanwhile, the integrated of the plan and the current condition do reflect the intensive principle; then the programs enable Xu Fu Village to cope with multidisciplinary issues like climate change, disaster risk reduction, economic crisis, and culture clash in the future. By providing modern agricultural, rural services, infrastructures, and also the cultural and nature preservation, the $\mathrm{Xu} F u$ Village LID Intensive Rural Construction planning demonstrates a good example of rural construction and development. In the future hopefully many others rural construction development can be review use many kinds of perspective and theories to compile recommendation for better rural planning.

\section{Acknowledgement}

Thank you to Zhejiang University and Ningbo Institute of Technology for providing "A Summary Report on the Implementation of Ningbo S \& T Projects" as the main data resource of Low Impact Development Intensive Rural Construction Planning in Xufu Village which used in this paper. This paper is supported by The People's Republic of China Specialized Research Fund for the Doctoral Program of Higher Education (No. 20130101110029)

\section{References}

Alexandre, E. (1967). Development Strategy and Planning: the Soviet Experience. Retrieved April 20, 2016, from http://www.nber.org/chapters/c1425.

Arup. (2012). Blueprint of the City Resilience Framework. Retrieved July 21, 2016, from http://publications.arup.com/publications/c/ city_resilience_framework.

Barata-Salgueiro, T., \& Erkip, F. (2014). Retail planning and urban resilience - An introduction to the special issue. Cities, 36, 107-111. doi:10.1016/j.cities.2013.01.007.

Chen, J., Guo, F., \& Wu, Y. (2011). One decade of urban housing reform in China: Urban housing price dynamics and the role of migration and urbanization, 1995-2005. Habitat International, 35(1), 1-8. 
doi:10.1016/j.habitatint.2010.02.003.

Ding, J., \& Hu, Z. (2016). Resilient water village landscape renovation planning with resilience concept. Journal Planning and Design, 6(32), 79-85. Retrieved from http://en.cnki.com.cn/Article_en/CJFDTOTALGHSI201606012.htm.

Feng, B. Y., Dong, L., \& Zhang, Y. (2006). Study on the Countermeasures of Rural Eco - Environmental Problems in the Perspective of Low Impact Development. Retrieved July 20, 2016, from http://www.cnki.net/kcms/detail/23.1528.TU.20160524.1000.032.html.

Folke, C., Carpenter, S., Elmqvist, T., Gunderson, L., \& Walker, B. (2002). Resilience and sustainable development : Building adaptive capacity in a world of transformations. AMBIO: A Journal of the Human Environment, 31(5), 437-440. doi:10.1579/0044-7447-31.5.437.

Godschalk, D. R. (2003). Urban hazard mitigation: Creating resilient cities. Natural Hazards Review, 4(3), 136143. doi:10.1061/(ASCE)1527-6988(2003)4:3(136).

Gu, C., Li, Y., \& Han, S. S. (2015). Development and transition of small towns in rural China. Habitat International, 50,110-119. doi:10.1016/j.habitatint.2015.08.017.

Holling, C. S. (1973). Resilience and stability of ecological systems. Annual Review of Ecology and Systematics, 4(1), 1-23. doi:10.1146/annurev.es.04.110173.000245.

Hosseini, S., Barker, K., \& Ramirez-Marquez, J. E. (2016). A review of definitions and measures of system resilience. Reliability Engineering and System Safety, 145, 47-61. doi:10.1016/j.ress.2015.08.006.

Hudson, R. (2010). Resilient regions in an uncertain world: Wishful thinking or a practical reality? Cambridge Journal of Regions, Economy and Society, 3(1), 11-25. doi:10.1093/cjres/rsp026.

Li, C. (2014). Research on Resilient Principles in Urban Planning based on Green Infrastructure Concept. University of Technology, Dalian, China.

Liu, Y., Zhang, F., \& Zhang, Y. (2009). Appraisal of typical rural development models during rapid urbanization in the Eastern Coastal Region of China. Journal of Geographical Sciences, 19(5), 557-567. doi:10.1007/s11442-009-0557-3.

Ma, L. J. C. (2005). Urban administrative restructuring, changing scale relations and local economic development in China. Political Geography, 24(4), 477-497. doi:1016/j.polgeo.2004.10.005.

Ouyang, M., \& Wang, Z. (2015). Resilience assessment of interdependent infrastructure systems: With a focus on joint restoration modeling and analysis. Reliability Engineering and System Safety, 141, 74-82. doi:10.1016/j.ress.2015.03.011.

Ploeg, V. Der, Jingzhong, Y., Schneider, S., \& Douwe, J. (2010). Rural development reconsidered : Building on comparative perspectives from China, Brazil and the European Union. Rivista Di Economia Agraria, 65(2), 163-190. Retrieved from https://www.cabdirect.org/cabdirect/abstract/20113224380.

Rescia, A. J., Pons, A., Lomba, I., Esteban, C., \& Dover, J. W. (2008). Reformulating the social-ecological system in a cultural rural mountain landscape in the Picos de Europa Region (Northern Spain). Landscape and Urban Planning, 88(1), 23-33. doi:10.1016/j.landurbplan.2008.08.001.

Schouten, S. (2009). Resilience : The philosophy of socio-ecological leeway. Ethnobotanical Knowledge Systems. Retrieved from https: / $/$ www.google.com/url?sa=t\&rct=j\&q=\&esrc=s\&source=web\&cd=1\&cad=rja\&uact=8\&ved=0ah UKEwjSiazE8frVAhXBsI8KHQ8vAQ0QFggmMAA\&url=http\%3A\%2F\%2Fsocrates.nu\%2Fwpcontent $\% 2$ Fuploads $\% 2$ F2012\%2F10\%2F2009-Essay-Resilience-and-agroecology.pdf\&usg=AFQjCNE98jY8lwfC46w_LXt8BevzbcU8fA.

Scott, M. (2013). Resilience: A conceptual lens for rural studies? Geography Compass, 79), 597-610. doi:10.1111/gec3.12066.

Sharifi, A., \& Yamagata, Y. (2014). Resilient urban planning: Major principles and criteria. Energy Procedia, 61, 1491-1495. doi:10.1016/j.egypro.2014.12.154.

Skerratt, S. (2013). Enhancing the analysis of rural community resilience: Evidence from community land ownership. Journal of Rural Studies, 31, 36-46. doi:10.1016/j.jrurstud.2013.02.003.

Walker, B., \& Salt, D. (2006). Resilience Thinking. Washington DC: Island Press.

Wardekker, J. A., de Jong, A., Knoop, J. M., \& van der Sluijs, J. P. (2010). Operationalising a resilience approach to adapting an urban delta to uncertain climate changes. Technological Forecasting and Social Change, 


\section{Low Impact Development Intensive Rural Construction Planning in Xu Fu Village Ningbo...}

776), 987-998. doi:10.1016/j.techfore.2009.11.005.

Wilson, G. A. (2012). Community resilience, globalization, and transitional pathways of decision-making. Geoforum, 43(6), 1218-1231. doi:10.1016/j.geoforum.2012.03.008.

Winderl, T. (2014). Disaster Resilience Measurements: Stocktaking of Ongoing Efforts in Developing Systems for Measuring Resilience. $\quad$ Retrieved September 11, 2016, from http://www.preventionweb.net/files/37916_disasterresiliencemeasurementsundpt.pdf.

Yuan, Q., Zhao, J. G., \& Xia, Y. Y. (2013). Research on rural planning strategies based on the coordination with the development of large-scale construction projects-a case study on Yanqing County in Beijing. Applied Mechanics and Materials, 357, 1882-1885. doi:10.4028/www.scientific.net/AMM.357-360.1882.

Zhang, L., \& Han, S. S. (2009). Regional disparities in China's urbanisation: An examination of trends 1982-2007. International Development Planning Review, 31(4), 355. doi:10.3828/idpr.2009.2.

Zhejiang University and Ningbo Institute of Technology. (2016). A Summary Report on the Implementation of Ningbo $S$ \& T Projects. Ningbo, China. Ningbo. 